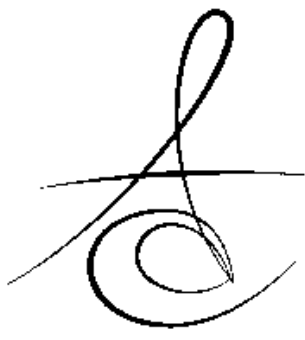

Makale Kodu/Article code: 2585

Makale Gönderilme tarihi: 03.02.2016

Kabul Tarihi: 13.04.2016

\section{ENDOKURONLAR: LİTERATÜR DERLEMESİ}

\author{
ENDOCROWNS: LITERATURE REVIEW
}

Dr. Saadet ÜNVER ${ }^{* *}$

\section{öz}

Endodontik tedavi görmüş dişlerin restorasyonu oldukça tartışmalı bir konudur. Endokuronlar, aşırı madde kaybına sahip endodontik tedavili dişlerin restorasyonunda, geleneksel post-kor restorasyonlara alternatif olarak kullanılmaktadır. Endokuron restorasyon tekniğinin temeli, pulpa odasından retansiyon ve stabilite desteği sağlayan adeziv bağlantıya dayanmaktadır. Basit, hızlı ve konservatif bir yöntem olması endokuronların avantajlarıdır. Bu derlemenin amacı, endokuron tekniği hakkında genel bilgiler vererek farklı restorasyon teknikleriyle birçok açıdan detaylı olarak karşılaştırmaktır.

Anahtar kelimeler: Endodontik tedavi edilmiş dişler, Endokuron, Kuron

\section{GİRİ̧̧}

Endodontik tedavi görmüş dişlerin restorasyonu, çok sayıda araştırma yapılmasına karşın, fikir birliğine varılamayan tartışmalı bir konudur. ${ }^{1} \mathrm{Bu}$ dişlerin uzun dönem klinik başarısında, endodontik tedavi sonrası uygulanan restorasyon en az endodontik tedavi kadar önemlidir. Uygun olmayan restoratif tedavi nedeniyle birçok endodontik tedavili diş kaybedilmektedir. Endodontik tedavi sonrası yapılan restorasyonların amacı, kalan diş dokusunun kırılmasını önlemek, koronal sızıntı yoluyla kök kanal sisteminin kontamine olmasını engellemek ve kaybedilen diş dokularını yerine koyarak, dişin fonksiyon görmesini sağlamaktır. $^{2-4}$

\section{ABSTRACT}

The restoration of endodontically treated teeth is a controversial topic from many perspectives. The endocrown is an alternative restorative option for severely damaged endodontically treated teeth instead of traditional post-core restorations. The foundation of this technique is based on the use of surface available in the pulpal chamber to assume the stability and retention of the restoration through adhesive procedures. Ease of application, being a quick and conservative technique are the advantages of endocrowns. The aim of this review article is to compare the endocrown technique with different restoration techniques in many respect by giving general information about this technique.

Key words: Endodontically-treated teeth, Endocrown, Crown

Endodontik tedavi görmüş dişler, vital dişlere kıyasla daha yüksek biyomekanik başarısızlık riski taşımaktadır. $^{5}$ Bunun temel nedeni, çürüğün temizlenmesi ve giriş kavitesi hazırlanması sırasında meydana gelen madde kaybıdır. Ayrıca endodontik tedavi sonrası dentinin dehidrate olması ve kollajen çapraz bağlarını kaybetmesi de dişin kırılma direncini olumsuz yönde etkilemektedir. ${ }^{6}$

Geleneksel yöntemlerle aşırı madde kaybına uğramış dişler endodontik tedaviyi takiben post-kor ve kuronlarla restore edilmektedir. ${ }^{7}$ Post uygulamalarının esas amacı aşıı koronal diş dokusu kaybı olan dişlerde kor yapı oluşturmaktır. ${ }^{8}$ Ancak post uygulaması restorasyonun kor kısmını kuvvetlendirmekle birlikte, kök kısmının zayıflamasına neden olabilir. Ayrıca post

\footnotetext{
* Başkent Üniversitesi, Diş Hekimliği Fakültesi, Protetik Diş Tedavisi AD.

***așkent Üniversitesi, Diș Hekimliăi Fakültesi, Endodonti AD.
} 
yerleştirilmesi sırasında kökte perforasyon ve kırık oluşma riski vardır. ${ }^{9}$ Adeziv başarısızık, post kırığı, endodontik başarısızlık ve ikincil çürük diğer başarısızlık nedenleri arasında sayılmaktadır. ${ }^{10} \mathrm{Bu}$ başarısızlıklar, protetik restorasyon öncesi post uygulamasının gerekliliğini sorgulanır hale getirmiştir. ${ }^{11-14}$

Kalan diş dokusunun miktarı ve kalitesi, yapılacak restorasyonun kırılma dayanımını ve retansiyonunu belirleyen iki ana faktördür. ${ }^{15}$ Travma, çürük ve endodontik prosedürler sonucu zayıflayan dişler kırığa daha yatkındır. Bu nedenle kalan diş dokusunun bütünlüğüne zarar vermeyecek ve kırılmaya karşı dayanıklılı̆ını arttıracak bir restorasyon tercih edilmelidir. ${ }^{16,}$

17 Aşırı madde kaybı olan endodontik tedavi görmüş dişlerin restorasyonu için 'endokuron' olarak adlandırılan alternatif bir restorasyon tekniği mevcuttur. Adeziv sistemlerdeki gelişmelere dayanan bu restorasyon tekniği 1995 yılında Pissis ${ }^{18}$ tarafından kor ve kuronu içeren monoblok bir yapı olarak tanımlanmıştır. Endokuron terimi ise ilk kez 1999 'da Bindl and Mörmann ${ }^{19}$ tarafından kullanılmıştır.

Adeziv sistemlerin uygulanmasında minimal invaziv preparasyonlarla maksimum diş dokusunun korunması esastır. Endokuronlar da bu prensiple uygulanmaktadır. ${ }^{20}$ Endokuronlar, pulpa odasının iç duvarlarına ve kavite marjinlerine bağlanmaktadır. Dolayısıyla makromekanik retansiyon pulpal duvarlardan, mikromekanik retansiyon ise adeziv simantasyon ile sağlanmaktadır. ${ }^{19}$ Endokuronlar, özellikle aşırı madde kaybı olan dişlerde, interproksimal mesafenin sınırlı olduğu ve geleneksel kuron restorasyonlarla yeterli seramik kalınlığının sağlanamadığı durumlarda endikedir. ${ }^{21}$ Ayrıca yetersiz interoklüzal mesafe ve aşırı madde kaybı nedeniyle ferrule etkisinin oluşturulamayacağı durumlarda uygulanmaktadır. ${ }^{22}$

\section{Endokuron Preparasyon Tekniği}

Endokuron preparasyonu yapılmadan önce diş üzerindeki eski dolgu materyalleri tamamen kaldırımalıdır. Pulpa odasındaki siman ve güta-perka artıkları temizlenmelidir. Sulkus içerisine retraksiyon kordu yerleştirilerek preparasyona başlanması önerilmektedir. Temel olarak endokuron preparasyonu, 1.0-1.2 $\mathrm{mm}$ derinliğinde çevresel servikal marjinlerden ve pulpa odasının içindeki retansiyon kavitesinden oluşmaktadır. ${ }^{18,}{ }^{19}$ Restore edilecek dişler standardize edilemediği için kavite prepasyonu da vakaya göre değişkenlik göstermekle beraber, premolar dişler için 3 $\mathrm{mm}$ çapında, $5 \mathrm{~mm}$ derinliğinde; molar dişler için 5 $\mathrm{mm}$ çapında, $5 \mathrm{~mm}$ derinliğinde retansiyon kavitesi önerilmektedir. ${ }^{18}$ Endokuronların oklüzal kalınlığı da genellikle 3-5 mm arasındadır. Tsai ve ark. ${ }^{23}$ oklüzal kalınlık arttıkça seramik kuronların kırıma dayanımlarının attığını göstermişlerdir. Mörmann ve ark. $^{24}$ ise $5.5 \mathrm{~mm}$ oklüzal kalınlığa sahip endokuronların kırılma dayanımlarının, $1.5 \mathrm{~mm}$ oklüzal kalınlığa sahip klasik preparasyonlu seramik kuronlardan daha yüksek olduğunu belirt- mişlerdir.

Endokuron uygulanmış klinik vakaların ve laboratuvar çalışmalarının sonuçları

Endokuronlar çok sayıda klinik takip çalışmaları ve laboratuvar çalışmaları ile incelenmiştir. İlk in vitro çalışmalardan olan Mörmann ve ark. ${ }^{24 \prime n ı n ~ a r a s ̧ t ı r-~}$ masında endokuron ve geleneksel kuronlar benzer kırılma dayanımı göstermiştir. 14-35 aylık bir klinik takip çalışmasında ise endokuronların başarılı sonuçları rapor edilmiştir. ${ }^{19}$ Bu klinik takipte sadece bir vakada ikincil çürük nedeniyle kayıp belirtilmiştir. ${ }^{19}$ Yaklaşık 5 yıl takip süresine sahip bir başka klinik çalışmada ise feldspatik molar endokuronların, geleneksel kuronlar kadar başarılı olduğu gösterilmiştir. Bu çalışmadaki endokuron başarısızlıkları ise vertikal kök kırıkları ve adeziv desimantasyondur. ${ }^{25}$

Molar endokuron uygulamalarını, premolar endokuronlar takip etmiştir. Premolar kompozit endokuronlarda yüksek marjinal sızıntı değerleri gösterilmiştir. ${ }^{26}$ Premolar endokuronlar in vitro olarak kompozitten üretildiğinde, geleneksel kompozit kuronlar kadar yüksek kırılma dayanımına sahiptir. ${ }^{26}$ Kompozit rezin kuronların elastik olarak deformasyona uğrayarak, kritik yükün kök dentinine iletilmesinden önce kırılması bu sonuçta etkilidir. Ancak klinik uygulamalarda feldspatik seramik premolar endokuronlar, geleneksel kuronlar ve molar endokuronlar kadar başarılı görülmemiştir. Premolar endokuronların daha az bağlantı yüzeyine sahip olması ve kuron tabanı ile kuron boyu oranın daha fazla kaldıraç kuvvetine neden olması başarısızlığın sebepleridir. ${ }^{25}$ Ancak sonlu elemanlar stres analizi ve Weilbull analizi ile cam fiberle güçlendirilmiş kompozit kor üzerine yapılan seramik kuron ve tek parça seramik endokuron restorasyonun başarısızlık riski premolarlar için benzer bulunmuştur. Endokuronlarda daha düşük hesaplanan stres değeri ise endokuronun monoblok tasarımından kaynaklanmaktadır. ${ }^{27}$ 
Seramik materyallerdeki gelişmeler ve ilerleyen bilgisayar destekli tasarım ve üretim [Computer Aided Design/Computer Aided Manufacture (CAD/CAM)] teknolojisi, endokuron uygulamalarına da yansımışırı. Valentina ve ark. ${ }^{28}$ CEREC 3D ve geleneksel Empress II teknikleriyle, güçlendirilmiş seramik materyalden endokuron üretmişlerdir. Üretim teknikleri farklı olan bu iki sistem de başarılı klinik sonuçlar göstermiştir. Ancak dijital ölçü ile üretilen endokuronlarda, restorasyonun kanallara doğru uzanan kısmının optik ölçünün sınırlamaları nedeniyle daha kısa olabileceği belirtilmiştir. Retansiyon kaybına neden olabilecek bu durumun, klinikte adeziv simantasyon ile kompanse edilebileceği söylenmiştir. Bir diğer çalışmada ise CEREC 3D CAD/CAM ünitesinde lösitle güçlendirilmiş seramik bloklardan üretilen endokuronların, geleneksel kuronlara kıyasla daha yüksek kırıma direncine sahip olduğu gösterilmiştir. ${ }^{21}$ Bu çalışmanın sonuçları Biacchi ve Basting'in ${ }^{29}$ lityum disilikat endokuronların, tam kuronlara kıyasla daha yüksek basma kuvvetlerine dayanabildiğini gösteren çalışması ile uyum göstermektedir. Biacchi ve Basting ${ }^{29}$ çalışmalarında ayrıca iki tip restorasyonun da basma kuvveti altındaki davranış biçimlerini incelemiştir. İki restorasyonda da en sık gözlenen kırılma şekli restorasyonun yerinden ayrılarak, diş ile birlikte kırımasıdır. Lityum disilikat endokuronun klinik başarısı sadece lingual duvarı olan bir molar dişte uygulanarak da gösterilmiştir. ${ }^{22} \mathrm{Bu}$ iki çalışmaya göre lityum disilikat cam seramiğin diş dokularına yüksek bağlanma kapasitesi ve bağlanma ara yüzlerinin daha az olması endokuronları başarılı kılmaktadır. ${ }^{22,}{ }^{29}$ Ara yüz sayısının azalmasının avantajı sonlu elemanlar stres analizi ile de gösterilmiştir. ${ }^{5}$ Diğer bir sonlu elemanlar stres analizi çalışmalarında ise oklüzal temasın, diş restorasyon birleşim hattına yakın olması halinde yük dağııımının daha elverişli olabileceğine ve seramik endokuronların daha düşük modifiye Von Misis stres seviyelerine neden olabileceğine değinilmiştir. ${ }^{30,31}$

Son yillarda kompozit ve porselenin olumlu özelliklerini bir araya getirdiği söylenen CAD/CAM rezin nano-seramik materyal tanıtılmıştır. Rocca ve ark., ${ }^{32}$ stres absorbe etme özelliği olduğu bilinen bu materyalden üretilen endokuronun klinik uygulamasını rapor etmiştir. Bu çalışmada endokuron kavitesine rezin kaplı iki yönlü cam fiber uygulamış, bu sayede dikey bir çatlağın alt katmanlara ilerlemesinin yavaşlatılması ya da durdurulması amaçlanmıştır. Ancak bir başka çalışmada kavite tabanına yerleştirilen fiber ağın vertikal köke doğru uzanan kırıkları durdurmada etkili olamadığı gösterilmiştir. ${ }^{33}$ Rocca ve ark. ${ }^{34}$ ise fiber ağın rezin nano-seramikten hazırlanan endokuronlarda marjinal uyumu bozmadığını göstermiştir. Aynı çalışmada termomekanik yükleme sonrası restorasyonların marjinal adaptasyonlarının azaldığı yine de kabul edilebilir sınırlarda olduğu da ifade edilmiştir. İki farklı çalışmada rezin nano seramik ve lityum disilikat cam seramik endokuronlar, post içermeyen kompozit kor üzerine yapılan geleneksel kuronlarla karşısştırımış; iki endokuron materyali de yorulma ve kırılma testleri sonuçlarına göre yeterli seviyede başarılı bulunmuştur. ${ }^{35,}{ }^{36} \mathrm{El}$-Damanhoury ve ark. $^{37}$ ise rezin nano-seramik materyal ile feldspatik seramik ve lityum disilikat cam seramikleri kırıma dayanımı açısından karşılaşııımışıı. Rezin nanoseramik materyalin, feldspatik porselen ve lityum disilikat cam seramik restorasyonlara kıyasla daha yüksek kırılma direnci ve daha az yıkıcı kırıma paternine sahip olduğu gösterilmiştir. Ancak marjinal sızıntı için farklı bulgulara rastlanmıştır. Seramik endokuronların daha düşük marjinal sızıntı gösterebileceği belirtilmiştir. ${ }^{37}$ Gregor ve ark. $^{38}$ ise endokuronlarda rezin polimerizasyonunun önemine dikkat çekmiştir. Dual polimerize ve ışıla polimerize olan iki rezin simanın da $7 \mathrm{~mm}$ kalınlığındaki endokuron restorasyonlarda yeterince polimerize olduğu gösterilmiştir.

\section{SONUÇ}

Adeziv sistemlerdeki ve seramiklerdeki gelişmelerle birlikte aşıı madde kaybı olan endodontik tedavi görmüş dişlerin restorasyonunda post-kor sistemlere daha az ihtiyaç duyulmaktadır. Endokuronlar geleneksel post-kor destekli kuron restorasyonlara alternatif olarak geliştirilmiş kor ve kuronu içeren monoblok bir yapıdır. Kompozit, feldspatik porselen, lityum disilikat cam seramik, lösitle güçlendirilmiş cam seramik, zirkonyum ve rezin nano-seramik mateyallerden üretilmektedir. Tüm bu materyallerle üretilen endokuronların başarılı klinik takipleri bulunmaktadır. İn vitro çalışmalarda ise sıklıkla endokuron restorasyonlar geleneksel kuronlara benzer kırıma dayanımı göstermiştir. Ancak restorasyonun uzun dönem başarısını etkileyen marjinal sızıntı özelliği ile ilgili daha fazla araştırma yapılması gerektiği düşünülmektedir. Ayrıca endokuron restorasyonun başarısı kullanılan adeziv sisteme bağlı olabilir, bu nedenle farklı adeziv 
sistemleriyle yapılacak çalışmalara da ihtiyaç duyulmaktadır

\section{KAYNAKLAR}

1. Robbins JW. Restoration of the endodontically treated tooth. Dent Clin North Am 2002;46:367-84.

2. Kirkevang LL, Orstavik D, Horsted-Bindslev $P$, Wenzel A. Periapical status and quality of root fillings and coronal restorations in a Danish population. Int Endod J 2000;33:509-15.

3. Tronstad L, Asbjornsen K, Doving L, Pedersen I, Eriksen HM. Influence of coronal restorations on the periapical health of endodontically treated teeth. Endod Dent Traumatol 2000;16:218-21.

4. Gillen BM, Looney SW, Gu LS, Loushine BA, Weller RN, Loushine RJ, Pashley DH, Tay FR. Impact of the quality of coronal restoration versus the quality of root canal fillings on success of root canal treatment: a systematic review and meta-analysis. J Endod 2011;37:895-902.

5. Zarone F, Sorrentino R, Apicella D, Valentino B, Ferrari M, Aversa R, Apicella A. Evaluation of the biomechanical behavior of maxillary central incisors restored by means of endocrowns compared to a natural tooth: a 3D static linear finite elements analysis. Dent Mater 2006;11:1035-44.

6. Assif D, Gorfil C. Biomechanical considerations in restoring endodontically treated teeth. J Prosthet Dent 1994;71:565-7.

7. Goodacre CJ, Spolnik KJ. The prosthodontic management of endodontically treated teeth: a literature review. Part I. Success and failure data, treatment concepts. J Prosthodont 1994;3:243-50.

8. Ahmetoğlu F, Şimşek N, Yıldıım G, Polat NT. Endodontik tedavili dişlerin restorasyonunda post materyalleri. Atatürk Üniv. Diş Hek. Fak. Derg 2014;24:153-7.

9. Schwartz RS, Robbins JW. Post placement and restoration of endodontically treated teeth: a literature review. J Endod 2004;30:289-301.

10. Barfeie A, Thomas MB, Watts A, Rees J. Failure Mechanisms of Fibre Posts: A Literature Review. Eur J Prosthodont Restor Dent 2015;23:115-27.

11. De Backer $H$, Van Maele G, De Moor N, Van den Berghe L, De Boever J. An 18-year retrospective survival study of full crowns with or without posts. Int J Prosthodont 2006;19:136-42.
12. Salvi GE, Siegrist Guldener BE, Amstad T, Joss A, Lang NP. Clinical evaluation of root filled teeth restored with or without post-and-core systems in a specialist practice setting. Int Endod J 2007;40:209-15.

13. Fokkinga WA, Kreulen CM, Bronkhorst EM, Creugers $\mathrm{NH}$. Composite resin core-crown reconstructions: an up to 17-year follow-up of a controlled clinical trial. Int J Prosthodont 2008;21:109-15.

14. Aurelio IL, Fraga S, Rippe MP, Valandro LF. Are posts necessary for the restoration of root filled teeth with limited tissue loss? A structured review of laboratory and clinical studies. Int Endod J 2015 doi: 10.1111/iej.12538

15. Ferrari M, Vichi A, Mannocci F, Mason PN. Retrospective study of the clinical performance of fiber posts. Am J Dent 2000;13:9-13.

16. Johnson JK, Schwartz NL, Blackwell RT. Evaluation and restoration of endodontically treated posterior teeth. J Am Dent Assoc 1976;93:597-605.

17. Linn J, Messer HH. Effect of restorative procedures on the strength of endodontically treated molars. J Endod 1994;20:479-85.

18. Pissis P. Fabrication of a metal-free ceramic restoration utilizing the monobloc technique. Pract Periodontics Aesthet Dent 1995;7:83-94.

19. Bindl A, Mormann WH. Clinical evaluation of adhesively placed Cerec endo-crowns after 2 years--preliminary results. J Adhes Dent 1999;1:255-65.

20. Dietschi D, Duc O, Krejci I, Sadan A. Biomechanical considerations for the restoration of endodontically treated teeth: a systematic review of the literature, Part II (Evaluation of fatigue behavior, interfaces, and in vivo studies). Quintessence Int 2008;39:117-29.

21. Chang $\mathrm{CY}$, Kuo JS, Lin YS, Chang YH. Fracture resistance and failure modes of CEREC endocrowns and conventional post and core-supported CEREC crowns. Journal of Dentai Sciences 2009;4:110-7.

22. Biacchi GR, Mello B, Basting RT. The endocrown: an alternative approach for restoring extensively damaged molars. J Esthet Restor Dent 2013;25:383-90. 
23. Tsai $Y L$, Petsche $P E$, Anusavice KJ, Yang MC. Influence of glass-ceramic thickness on Hertzian and bulk fracture mechanisms. Int J Prosthodont 1998;11:27-32.

24. Mormann WH, Bindl A, Luthy $H$, Rathke A. Effects of preparation and luting system on all-ceramic computer-generated crowns. Int J Prosthodont 1998;11:333-9.

25. Bindl A, Richter B, Mormann WH. Survival of ceramic computer-aided design/manufacturing crowns bonded to preparations with reduced macroretention geometry. Int J Prosthodont 2005;18:219-24.

26. Stricker EJ, Gohring TN. Influence of different posts and cores on marginal adaptation, fracture resistance, and fracture mode of composite resin crowns on human mandibular premolars. An in vitro study. J Dent 2006;34:326-35.

27. Lin $\mathrm{CL}$, Chang $\mathrm{YH}$, Chang $\mathrm{CY}$, Pai CA, Huang SF. Finite element and Weibull analyses to estimate failure risks in the ceramic endocrown and classical crown for endodontically treated maxillary premolar. Eur J Oral Sci 2010;118:87-93.

28. Valentina V, Aleksander T, Dejan T, Vojkan L. Restoring endodontically treated teeth with allceramic endo-crowns- case report. Stom Glas S 2008;55:54-64.

29. Biacchi GR, Basting RT. Comparison of fracture strength of endocrowns and glass fiber postretained conventional crowns. Oper Dent 2012;37:130-6.

30. Dejak B, Mlotkowski A. 3D-Finite element analysis of molars restored with endocrowns and posts during masticatory simulation. Dent Mater 2013;29:e309-17.

31. Hasan I, Frentzen M, Utz KH, Hoyer D, Langenbach A, Bourauel $C$. Finite element analysis of adhesive endo-crowns of molars at different height levels of buccally applied load. J Dent Biomech 2012;3:1758736012455421. doi: $10.1177 / 1758736012455421$

32. Rocca GT, Rizcalla N, Krejci I. Fiber-reinforced resin coating for endocrown preparations: a technical report. Oper Dent 2013;38:242-8.

33. Rocca GT, Saratti CM, Cattani-Lorente M, Feilzer AJ, Scherrer S, Krejci I. The effect of a fiber reinforced cavity configuration on load bearing capacity and failure mode of endodontically treated molars restored with CAD/CAM resin composite overlay restorations. J Dent 2015;43:1106-15.

34. Rocca GT, Saratti CM, Poncet A, Feilzer AJ, Krejci I. The influence of FRCs reinforcement on marginal adaptation of CAD/CAM composite resin endocrowns after simulated fatigue loading. Odontology 2015. doi: 10.1007/s10266-015-02029

35. Carvalho AO, Bruzi G, Anderson RE, Maia HP, Giannini M, Magne P. Influence of Adhesive Core Buildup Designs on the Resistance of Endodontically Treated Molars Restored With Lithium Disilicate CAD/CAM Crowns. Oper Dent 2016;41:76-82.

36. Magne P. IDS: Immediate Dentin Sealing (IDS) for tooth preparations. J Adhes Dent 2014;16:594.

37. El-Damanhoury HM, Haj-Ali RN, Platt JA. Fracture resistance and microleakage of endocrowns utilizing three CAD-CAM blocks. Oper Dent 2015;40:201-10.

38. Gregor L, Bouillaguet S, Onisor I, Ardu S, Krejci I, Rocca GT. Microhardness of light- and dualpolymerizable luting resins polymerized through 7.5-mm-thick endocrowns. J Prosthet Dent 2014;112:942-8.

\author{
Yazışma Adresi \\ Dr. Özlem ACAR \\ Başkent Üniveristesi \\ Diş Hekimliği Fakültesi \\ 11. sok NO:26 \\ TIf: 03124386533 \\ e-mail: zlemacr@gmail.com
}

